\title{
Detection of Heterozygotes for Phenylketonuria by Column Chromatography and Discriminatory Analysis
}

\author{
S. Rampini ${ }^{[35]}$, P.W. Anders, H. Gh. Gurtius, and Th. Marthaler \\ Department of Pediatrics and Medical Biostatistical Center, University of Zurich, Switzerland
}

\begin{abstract}
Extract
Phenylalanine $(100 \mathrm{mg} / \mathrm{kg})$ was administered orally to 19 parents of patients with phenylketonuria and to 26 control subjects. Concentrations of phenylalanine and tyrosine in plasma were determined by column chromatography before phenylalanine administration and at 1, 2, 3, and 4 hours after loading. The values of two control subjects (C 21 and C 25) and of two parents (P 4 and P 6) were unusually low or high. Excluding subjects $\mathrm{C} 21, \mathrm{C} 25, \mathrm{P} 4$, and P6, the following calculations of the values after loading were made:

Mean and SD of mean of phenylalanine levels at each time: in spite of a significant difference, there was a slight overlap.

Sum of the phenylalanine values: significant difference, no overlap.

Sum of the phenylalanine/tyrosine ratios: significant difference, no overlap.

Using these criteria, control subjects $\mathrm{C} 21$ and C 25 were considered to be heterozygotes. The values of subject P 4 (father of a known patient) were within the range of the control group; paternity was excluded by blood group analysis. The values of subject P 6 were unusually high and could not be explained satisfactorily.

The concentrations of phenylalanine and tyrosine after loading were evaluated by discriminatory analysis. Thus, subjects C 21, C 25, and P 4 were excluded, but values were calculated both including and excluding subject $\mathrm{P} 6$. To compare the different criteria of evaluation, the index of PenRose (discriminatory power $=\mathrm{D} / \overline{\mathrm{s}}$ ) was calculated. A better separation was obtained with discriminatory analysis than with the sum of the phenylalanine values or of the phenylalanine/tyrosine ratios. The use of column chromatography and evaluation by discriminatory analysis seems to improve the possibilities of detection of heterozygotes for phenylketonuria.
\end{abstract}

\section{Speculation}

With discriminatory analysis, the separation of heterozygotes for phenylketonuria from normal subjects was better than with other criteria of evaluation. We believe that this method could be used successfully for determination of heterozygosity in other inborn errors of metabolism with recessive inheritance when several variables are available for each subject examined. 


\section{Introduction}

Hsia et al. $[11,12]$ first demonstrated that following an oral phenylalanine load, plasma concentrations of phenylalanine were significantly higher in parents of patients with phenylketonuria than in control subjects; however, there was some overlap in individual values. In an effort to obtain a better separation of heterozygotes and normal subjects, different conditions of testing and criteria of statistical analysis were subsequently used by several investigators $[1,3,4,9,10$, $13,15,21,22,23,28-30]$, but separation was never completely satisfactory.

This report is a new study of oral phenylalanine loads in which the concentrations of phenylalanine and tyrosine in plasma were determined by column chromatography and evaluated by discriminatory analysis [26].

\section{Subjects and Methods}

Nineteen parents of patients with phenylketonuria were compared with 26 control subjects having negative family histories of phenylketonuria.

L-phenylalanine $(100 \mathrm{mg} / \mathrm{kg}$ body weight) was administered in a mixture of $100 \mathrm{ml}$ orange juice and $100 \mathrm{ml}$ water after an overnight fast. Five samples of heparinized venous blood were obtained before and 1, 2, 3 and 4 hours after loading.

An $0.2 \mathrm{ml}$ sample of plasma was deproteinized immediately with $0.8 \mathrm{ml}$ of 5 percent sulfosalicylic acid. After centrifugation, the supernatant was frozen at $-20^{\circ}$. Analysis was carried out with an amino acid analyzer with an automatic programming device [31] according to the method of Spackman et al. [27]. It was performed with a short program for phenylalanine and tyrosine based on methods reported previously $[2,16,19,25]$. A $42 \times 0.9 \mathrm{~cm}$ column, packed with spheric Bio Rad -A5 cation exchange resin (height $22 \mathrm{~cm}$ ) of particle size $12-15 \mu$ was used. For elution, a $0.35 \mathrm{n}$ sodium citrate buffer $(\mathrm{pH} 5.28)$ was used, and for regeneration, a $0.4 \mathrm{n} \mathrm{NaOH}$ was used. The flow rates of buffer and ninhydrine reagent were 80 and $40 \mathrm{ml} / \mathrm{h}$, respectively, at a column temperature of $57^{\circ}$.

The expansion of the measuring range in a Honeywell recorder from $0-5 \mathrm{mV}$ to $2.5-5.0 \mathrm{mV}$ allowed the use of regular cuvettes. The programmed course of analysis was as follows:

$\begin{array}{llll}\text { Eluate } & \mathrm{pH} 5.28 & \mathrm{NaOH} & \mathrm{pH} 5.28 \\ \text { Time (min) } & 0-7 & 7-15 & 15-41\end{array}$

The ninhydrine pump and the recorder were stopped at 29 minutes. Thus, time was saved by starting regeneration and equilibration of the column before the end of the analyses. Up to 10 analyses (plus one anal- ysis of a standard mixture) were carried out in one working day.

For this short program, only one buffer was necessary. For good separation of tyrosine and phenylalanine, a high column temperature was more important than the $\mathrm{pH}$ of the buffer.

\section{Results and Statistical Evaluation}

The values of phenylalanine and tyrosine before and after loading are shown in table I (controls) and table II (parents). As expected, the phenylalanine concentrations after loading were higher in the heterozygotes and the tyrosine concentrations were higher in the control subjects. In the control group, however, unusually high phenylalanine and low tyrosine concentrations were found in two control subjects, C 21 and C 25, after loading. Unusual values were also found in two parents. Subject $P 4$ had low phenylalanine and high tyrosine values and subject $P 6$ had very high phenylalanine and low tyrosine concentrations. For better analysis of these four subjects, the following calculations were made:

1. Mean values and standard deviations of the concentration of phenylalanine in the two groups each hour after load, excluding subjects C 21, C 25, P 4, and $\mathrm{P} 6$ (table IV, fig. 1).

2. Sum of the phenylalanine concentrations of all subjects 1, 2, 3, and 4 hours after loading (tables I and II, fig. 2); mean and standard deviation, excluding subjects C $21, \mathrm{C} 25, \mathrm{P} 4$, and P 6 (table IV).

3. Sum of the phenylalanine/tyrosine ratios of all subjects 1, 2, 3, and 4 hours after loading (tables I and II, fig. 2); mean and standard deviation, excluding subjects C 21, G 25, P 4, and P 6 (table IV). The phenylalanine/tyrosine ratio $=$ plasma phenylalanine $\mathrm{mg} / 100 \mathrm{ml}$ divided by plasma tyrosine $\mathrm{mg} / 100 \mathrm{ml}$.

Excluding the four subjects with unusual values (C21, C25, P4, and P 6), the 24 control subjects, whose values were analyzed by use of the three calculations, represented a homogenous group with a small variability; the variability was larger in the 17 heterozygotes. The difference between the two groups was significant. If calculation 1 was applied, there was some overlap between the two groups. If calculations 2 and 3 were used, the two groups were completely separated (table IV).

\section{The Two Unusual Control Subjects}

In subjects $\mathrm{C} 21$ and $\mathrm{C} 25$, concentrations of phenylalanine in plasma were definitely in the range of the heterozygotes (fig. 1). The phenylalanine concentrations at hours 2, 3, and 4 were more than $3 \mathrm{SD}$ above the values of the other 24 controls. They were also in 
Table I. Oral L-phenylalanine load. Results in 26 controls

\begin{tabular}{|c|c|c|c|c|c|c|c|c|c|c|c|c|c|c|c|c|c|}
\hline \multirow{2}{*}{ 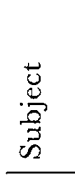 } & \multirow[b]{2}{*}{ 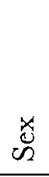 } & \multirow{2}{*}{ 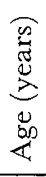 } & \multirow{2}{*}{ 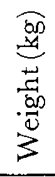 } & \multicolumn{5}{|c|}{$\begin{array}{c}\text { Phenylalanine } \\
\mathrm{mg} / 100 \mathrm{ml} \text { plasma }\end{array}$} & \multicolumn{5}{|c|}{$\begin{array}{c}\text { Tyrosine } \\
\mathrm{mg} / 100 \mathrm{ml} \text { plasma }\end{array}$} & \multirow{2}{*}{$\begin{array}{c}\sum \mathrm{Phe}^{\mathrm{l}} \\
\mathrm{mg} / \\
100 \mathrm{ml}\end{array}$} & \multirow[t]{2}{*}{$\begin{array}{c}\Sigma(\text { Phe/ } \\
\text { Tyr })^{2}\end{array}$} & \multicolumn{2}{|c|}{$\frac{\text { Discriminant score }^{3}}{\text { Formula 1 Formula } 2}$} \\
\hline & & & & $0 \mathrm{~h}$ & $1 \mathrm{~h}$ & $2 \mathrm{~h}$ & $3 \mathrm{~h}$ & $4 \mathrm{~h}$ & $\mathrm{Oh}$ & $1 \mathrm{~h}$ & $2 \mathrm{~h}$ & $3 \mathrm{~h}$ & $\overline{4 h}$ & & & P6) & $\begin{array}{l}\text { (without } \\
\text { P 6) }\end{array}$ \\
\hline C 1 & $\mathrm{~m}$ & 26 & 78 & 0.94 & 8.07 & 7.54 & 5.00 & 3.35 & 1.19 & 2.57 & 3.10 & 3.28 & 3.22 & 23.96 & 8.13 & 2.094 & 1.219 \\
\hline $\mathrm{C} 2$ & $f$ & 23 & 56 & 1.06 & 6.42 & 8.22 & 6.06 & 4.74 & 1.05 & 2.28 & 2.61 & 2.95 & 2.88 & 25.44 & 9.67 & 1.867 & 3.149 \\
\hline C 3 & $\mathrm{f}$ & 20 & 48 & 0.68 & 11.24 & 7.11 & 5.07 & 2.72 & 1.06 & 2.24 & 2.23 & 2.46 & 1.70 & 26.14 & 11.87 & 2.814 & 4.346 \\
\hline G 4 & $\mathrm{~m}$ & 19 & 63 & 0.77 & 7.21 & 6.68 & 3.63 & 3.47 & 1.09 & 1.68 & 2.46 & 2.05 & 2.33 & 20.99 & 10.27 & 0.883 & 1.841 \\
\hline C 5 & $\mathrm{~m}$ & 24 & 61 & 0.77 & 8.40 & 7.61 & 5.16 & 3.25 & 1.02 & 2.21 & 3.08 & 2.44 & 2.28 & 24.42 & 9.81 & 1.610 & 3.429 \\
\hline C 6 & $\mathrm{~m}$ & 20 & 65 & 0.68 & 7.46 & 6.06 & 4.82 & 3.40 & 0.80 & 2.50 & 2.52 & 2.77 & 2.46 & 21.74 & 8.50 & -1.094 & 0.064 \\
\hline G 7 & $\mathrm{~m}$ & 32 & 76 & 0.82 & 14.78 & 5.59 & 4.42 & 3.28 & 1.13 & 2.50 & 2.46 & 2.44 & 2.46 & 28.07 & 11.32 & 5.776 & 5.328 \\
\hline C 8 & $\mathrm{~m}$ & 19 & 64 & 0.75 & 11.47 & 6.50 & 4.44 & 3.25 & 0.97 & 2.66 & 3.24 & 2.44 & 2.64 & 25.66 & 9.37 & 2.502 & 2.520 \\
\hline C 9 & $\mathrm{f}$ & 30 & 52 & 0.75 & 8.43 & 5.43 & 3.02 & 2.06 & 1.09 & 3.04 & 3.00 & 2.12 & 1.92 & 18.94 & 7.07 & -4.631 & -4.880 \\
\hline G 10 & $\mathrm{~m}$ & 42 & 51 & 0.78 & 10.69 & 6.06 & 3.40 & 2.28 & 1.26 & 2.79 & 2.70 & 2.88 & 2.28 & 22.43 & 8.25 & -4.073 & -3.396 \\
\hline C 11 & $f$ & 20 & 49 & 0.78 & 11.12 & 7.95 & 5.30 & 2.89 & 1.09 & 2.39 & 2.72 & 2.70 & 2.15 & 27.26 & 10.87 & 3.685 & 4.443 \\
\hline C 12 & $\mathrm{~m}$ & 36 & 65 & 0.90 & 11.30 & 6.62 & 3.63 & 2.64 & 0.79 & 2.28 & 2.33 & 1.77 & 1.50 & 24.19 & 11.61 & 1.066 & 1.766 \\
\hline C 13 & $\mathrm{f}$ & 19 & 53 & 0.82 & 11.09 & 9.90 & 6.06 & 3.27 & 1.08 & 2.60 & 3.26 & 3.35 & 2.66 & 30.32 & 10.35 & 2.997 & 4.050 \\
\hline C 14 & $f$ & 20 & 57 & 1.08 & 8.43 & 8.68 & 6.24 & 5.21 & 1.46 & 2.53 & 3.04 & 3.31 & 3.57 & 28.56 & 9.54 & 3.862 & 3.998 \\
\hline C 15 & $f$ & 22 & 45 & 1.10 & 10.56 & 5.86 & 3.96 & 2.56 & 1.28 & 2.75 & 2.75 & 2.44 & 1.81 & 22.94 & 9.00 & -4.523 & -1.987 \\
\hline C 16 & $\mathrm{f}$ & 18 & 52 & 1.06 & 10.89 & 8.10 & 5.11 & 3.50 & 1.42 & 2.64 & 3.22 & 3.53 & 3.17 & 27.60 & 9.20 & 0.173 & 1.140 \\
\hline G 17 & $f$ & 35 & 58 & 1.14 & 12.64 & 6.47 & 4.82 & 3.66 & 1.65 & 3.31 & 3.62 & 3.11 & 3.04 & 27.59 & 8.36 & -2.078 & -0.827 \\
\hline G 18 & $f$ & 23 & 61 & 1.14 & 9.08 & 6.85 & 5.46 & 3.70 & 1.41 & 2.46 & 3.08 & 3.40 & 3.28 & 25.09 & 8.65 & 1.805 & 2.673 \\
\hline C 19 & $f$ & 23 & 45 & 0.91 & 7.89 & 5.12 & 3.98 & 3.25 & 0.91 & 1.74 & 2.17 & 2.14 & 2.39 & 20.24 & 10.11 & 3.612 & 3.767 \\
\hline C 20 & $\mathrm{~m}$ & 38 & 60 & 1.26 & 13.15 & 6.55 & 5.61 & 3.30 & 1.62 & 3.46 & 2.95 & 3.40 & 2.57 & 28.61 & 8.95 & -1.495 & -0.139 \\
\hline C 21 & $\mathrm{~m}$ & 34 & 75 & 1.78 & 14.12 & 15.71 & 11.62 & 9.72 & 1.38 & 1.74 & 1.61 & 1.83 & 1.86 & 51.17 & 29.46 & 19.559 & 23.628 \\
\hline G 22 & $\mathrm{f}$ & 25 & 54 & 1.01 & 7.06 & 6.24 & 4.59 & 3.22 & 1.23 & 2.50 & 2.79 & 3.10 & 2.69 & 21.11 & 7.74 & -3.601 & -1.729 \\
\hline C 23 & $\mathrm{~m}$ & 27 & 58 & 1.06 & 7.71 & 5.31 & 3.50 & 2.31 & 1.03 & 2.06 & 2.43 & 2.37 & 1.90 & 18.83 & 8.63 & -3.667 & -1.263 \\
\hline G 24 & $\mathrm{~m}$ & 31 & 61 & 0.96 & 5.13 & 6.91 & 4.31 & 2.99 & 1.12 & 1.81 & 2.10 & 2.05 & 1.83 & 19.34 & 9.85 & 1.117 & 1.731 \\
\hline C 25 & $f$ & 23 & 64 & 0.90 & 14.04 & 12.21 & 7.97 & 5.40 & 0.97 & 1.38 & 1.56 & 1.67 & 1.72 & 39.62 & 25.91 & 22.041 & 20.423 \\
\hline C 26 & $\mathrm{~m}$ & 34 & 59 & 1.00 & 9.65 & 8.46 & 4.09 & 2.74 & 1.00 & 2.73 & 3.57 & 3.11 & 2.64 & 24.94 & 8.26 & -4.670 & -2.862 \\
\hline
\end{tabular}

1 Sum of the phenylalanine concentrations 1, 2, 3, and 4 hours after load.

${ }^{2}$ Sum of the phenylalanine/tyrosine ratios $1,2,3$, and 4 hours after load.

${ }^{3}$ For explanation see text and table III. 


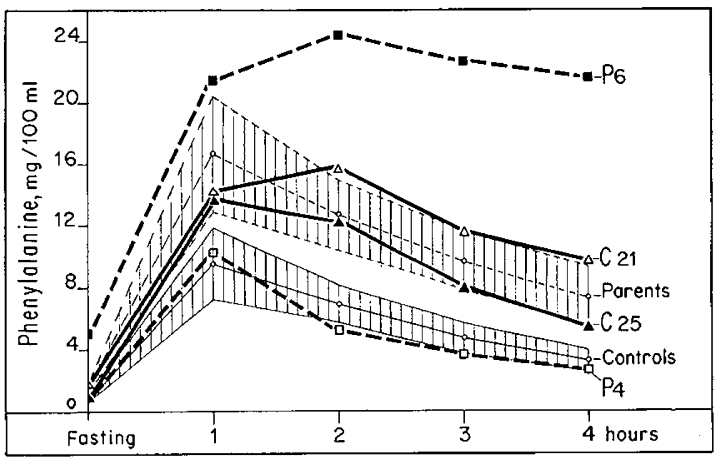

Fig. 1. Results of oral L-phenylalanine load $(100 \mathrm{mg} /$ $\mathrm{kg}$ ). Plasma phenylalanine concentrations. Hatched areas: mean $\pm 1 \mathrm{SD}$ at each time in 24 of 26 controls (C 21 and C. 25 excluded) and in 17 of 19 parents (P 4 and P 6 excluded). The values of C 21, C 25, P 4 and $P 6$ are shown individually.

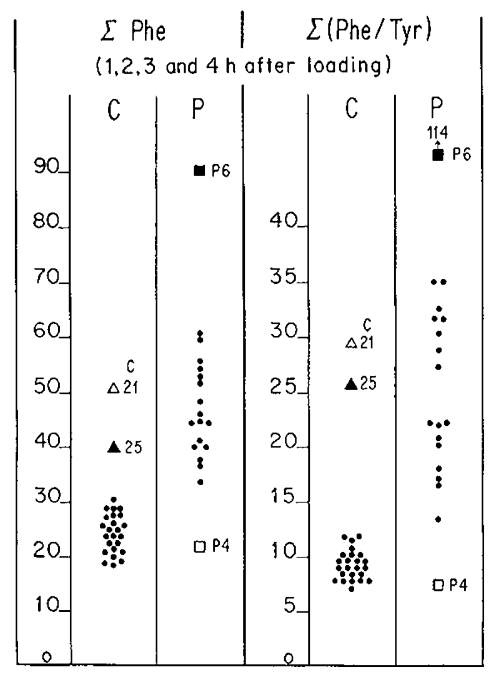

Fig. 2. Results of oral L-phenylalanine load $(100 \mathrm{mg} /$ $\mathrm{kg}) .26$ controls $(\mathrm{C})$ and 19 parents $(\mathrm{P})$. Left: sum of the plasma phenylalanine concentrations $1,2,3$, and 4 hours after load. Right: sum of the phenylalanine/ tyrosine ratios 1, 2, 3, and 4 hours after load.

Fig.3. Results of oral L-phenylalanine load (100 mg/ $\mathrm{kg})$. Individual discriminant scores in all 26 controls (C) and in all 19 parents (P). C 21, C 25, and P 4 were excluded from the discriminatory analysis. Formula 1 : $\mathrm{P} 6$ included in the discriminatory analysis. Formula 2: P 6 excluded. The line between the controls and the heterozygotes represents the critical line according to Penrose (see table IV). the range of the heterozygotes and more than $3 \mathrm{SD}$ above the values of the other 24 controls if calculations 2 and 3 were applied (fig. 2).

The frequency of the heterozygotes for phenylketonuria in the general population is believed to be $1: 50$ $[5-8,17,18]$. Each individual in the control group had therefore a probability of $1: 50$ of being a heterozygote. By binomial distribution, it can be calculated that a random sample of 26 subjects will include two heterozygotes with a probability of $8 \%$ [32]. Since the values of subjects C 21 and C 25 were well within the range for heterozygotes, these subjects were considered as such and were excluded from the sample on which discriminatory analysis was performed.

\section{The Two Unusual Parents}

The values of subject $\mathrm{P} 4$ (father of a known patient) were definitely within the control range using all three calculations (figs. 1 and 2). Paternity could be excluded with practical certainty by blood group analysis in this family [33]. Subject P 4 was therefore omitted for discriminatory analysis. In subject P 6 (mother of a known patient, but not married to subject $P$ 4), the initial increase of phenylalanine concentration after loading was not unusually high, but the values remained considerably elevated at the 2nd, 3rd, and 4th hour after loading (fig. 1). In this case, the fasting phenylalanine concentration was already unusually high $(4.97 \mathrm{mg} /$ $100 \mathrm{mI}$ ). Tyrosine concentrations after loading remained very low and the sums of the phenylalanine values and of the phenylalanine/tyrosine ratios were excessively high (table II, fig. 2). This behavior remains unexplained.

\section{Discriminatory Analysis}

For the purpose of this study, only the unquestionable subjects were considered, and subjects C 21, C 25, and $\mathrm{P} 4$ were therefore excluded. Discriminatory anal-

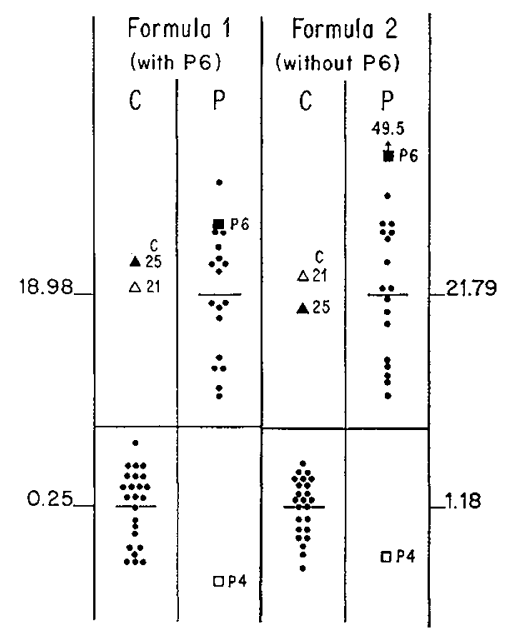


Table II. Oral L-phenylalanine load. Results in 19 parents

\begin{tabular}{|c|c|c|c|c|c|c|c|c|c|c|c|c|c|c|c|c|c|}
\hline \multirow[b]{2}{*}{ 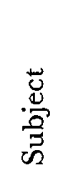 } & \multirow[b]{2}{*}{$\stackrel{x}{\mathscr{S}}$} & \multirow{2}{*}{ 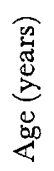 } & \multirow{2}{*}{ 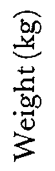 } & \multicolumn{5}{|c|}{$\begin{array}{c}\text { Phenylalanine } \\
\text { mg/100 ml plasma }\end{array}$} & \multicolumn{5}{|c|}{$\begin{array}{c}\text { Tyrosine } \\
\mathrm{mg} / 100 \mathrm{ml} \text { plasma }\end{array}$} & \multirow{2}{*}{$\begin{array}{c}\Sigma \mathrm{Phe}^{1} \\
\mathrm{mg} / \\
100 \mathrm{ml}\end{array}$} & \multirow[t]{2}{*}{$\begin{array}{l}\Sigma(\mathrm{Phe} / \\
\text { Tyr })^{2}\end{array}$} & \multicolumn{2}{|c|}{$\frac{\text { Discriminant score }^{3}}{\text { Formula } 1 \text { Formula } 2}$} \\
\hline & & & & $\overline{0 \mathrm{~h}}$ & $1 \mathrm{~h}$ & $2 \mathrm{~h}$ & $3 \mathrm{~h}$ & $\overline{4 h}$ & $\overline{0 h}$ & $1 \mathrm{~h}$ & $2 \mathrm{~h}$ & $3 \mathrm{~h}$ & $\overline{4 h}$ & & & with P 6) & $\begin{array}{l}\text { (without } \\
\text { P 6) }\end{array}$ \\
\hline P 1 & $f$ & 26 & 62 & 1.02 & 12.75 & 9.14 & 7.13 & 4.64 & 1.23 & 2.21 & 2.72 & 2.79 & 2.82 & 33.66 & 13.34 & 12.232 & 12.000 \\
\hline P 2 & $\mathrm{~m}$ & 30 & 83 & 1.53 & 11.65 & 11.04 & 8.86 & 8.35 & 1.21 & 1.85 & 1.63 & 1.73 & 1.99 & 39.90 & 22.39 & 10.560 & 14.894 \\
\hline P 3 & $f$ & 25 & 52 & 1.23 & 18.85 & 11.14 & 8.63 & 5.69 & 0.66 & 1.70 & 2.63 & 2.76 & 2.52 & 44.31 & 20.70 & 16.822 & 20.018 \\
\hline P 4 & $\mathrm{~m}$ & 36 & 75 & 1.27 & 10.26 & 5.26 & 3.70 & 2.61 & 1.32 & 2.90 & 3.22 & 2.82 & 2.41 & 21.83 & 7.56 & -6.381 & -3.788 \\
\hline P 5 & $\mathrm{f}$ & 39 & 55 & 1.03 & 11.53 & 11.24 & 8.51 & 5.33 & 0.78 & 1.76 & 2.41 & 2.66 & 2.30 & 36.61 & 16.73 & 13.304 & 15.374 \\
\hline P 6 & $\mathrm{f}$ & 28 & 62 & 4.97 & 21.58 & 24.45 & 22.69 & 21.58 & 1.01 & 0.80 & 0.80 & 0.80 & 0.76 & 90.30 & 114.29 & 25.089 & 49.539 \\
\hline P 7 & $\mathrm{~m}$ & 32 & 55 & 1.31 & 21.83 & 13.32 & 10.41 & 7.46 & 1.20 & 1.56 & 1.77 & 1.83 & 1.65 & 53.02 & 31.73 & 24.465 & 27.753 \\
\hline P 8 & $\mathrm{f}$ & 34 & 64 & 1.35 & 22.97 & 16.81 & 12.24 & 8.58 & 1.10 & 1.77 & 2.33 & 2.50 & 2.33 & 60.60 & 28.77 & 28.744 & 31.377 \\
\hline P 9 & $\mathrm{~m}$ & 33 & 85 & 1.25 & 16.96 & 13.05 & 8.79 & 6.30 & 1.04 & 1.45 & 1.68 & 1.97 & 1.90 & 45.10 & 27.25 & 22.012 & 22.283 \\
\hline P 10 & $f$ & 39 & 51 & 1.33 & 15.38 & 10.65 & 6.88 & 4.80 & 1.32 & 2.01 & 2.32 & 2.14 & 1.94 & 37.71 & 17.92 & 12.495 & 13.344 \\
\hline P 11 & $\mathrm{~m}$ & 39 & 73 & 1.61 & 20.39 & 15.81 & 10.03 & 9.31 & 1.28 & 1.59 & 1.74 & 1.34 & 1.67 & 55.54 & 34.97 & 21.175 & 24.826 \\
\hline P 12 & $f$ & 38 & 54 & 1.42 & 15.91 & 15.91 & 12.69 & 9.83 & 1.33 & 1.48 & 1.92 & 1.99 & 1.99 & 54.34 & 30.36 & 23.035 & 28.506 \\
\hline P 13 & $\mathrm{~m}$ & 67 & 74 & 1.48 & 22.54 & 14.70 & 11.70 & 10.54 & 1.38 & 1.59 & 1.72 & 1.72 & 1.94 & 59.48 & 34.96 & 21.623 & 28.621 \\
\hline P 14 & $f$ & 30 & 65 & 1.17 & 14.32 & 15.13 & 12.49 & 9.92 & 0.71 & 1.36 & 1.76 & 1.76 & 1.86 & 51.86 & 31.56 & 21.812 & 27.736 \\
\hline P 15 & $\mathrm{~m}$ & 36 & 75 & 1.23 & 14.70 & 11.07 & 8.04 & 6.42 & 1.01 & 1.92 & 2.73 & 2.73 & 2.70 & 40.23 & 17.04 & 9.873 & 13.851 \\
\hline P 16 & $\mathrm{f}$ & 33 & 60 & 1.25 & 18.15 & 10.21 & 7.66 & 5.03 & 0.97 & 1.70 & 1.97 & 2.10 & 1.90 & 41.05 & 22.16 & 18.026 & 19.006 \\
\hline P 17 & $\mathrm{~m}$ & 34 & 80 & 1.28 & 18.63 & 12.44 & 10.03 & 7.11 & 0.82 & 1.25 & 1.63 & 1.70 & 1.70 & 48.21 & 32.61 & 24.565 & 27.188 \\
\hline P 18 & $\mathrm{f}$ & 42 & 57 & 1.39 & 15.11 & 12.29 & 10.03 & 8.40 & 1.28 & 1.63 & 2.17 & 2.50 & 2.88 & 45.83 & 21.86 & 18.092 & 21.419 \\
\hline P 19 & $\mathrm{~m}$ & 51 & 80 & 1.41 & 12.21 & 11.60 & 11.76 & 8.66 & 1.57 & 2.05 & 2.10 & 2.32 & 2.37 & 44.23 & 20.20 & 17.683 & 22.207 \\
\hline
\end{tabular}

${ }^{1}$ Sum of the phenylalanine concentrations $1,2,3$, and 4 hours after load.

${ }^{2}$ Sum of the phenylalanine/tyrosine ratios $1,2,3$, and 4 hours after load.

${ }^{3}$ For explanation see text and table III. 
ysis [26] was then performed with and without subject $P$ 6. With this statistical method, the individual variables were combined by coefficients to a discriminant score for each subject, and the best possible separation of two groups was obtained. In each subject, 10 measurements or 10 variables (5 phenylalanine and 5 tyrosine values) were available. Various combinations of the variables were chosen. In the present context, only the results of discriminatory analysis using all phenylalanine and tyrosine concentrations after loading (a total of 8) are presented.

The coefficients are shown in table III. Formula 1 was obtained including subject P 6 and formula 2 was obtained excluding this subject. The signs of the coefficients agreed in both formulae, but size showed considerable difference.

The discriminant scores (for calculation, see table III) of the 26 control subjects and of the 19 parents are shown in tables I and II and in figure 3. In figure 3, the critical line separating the scores of the two groups (see table IV) is also shown. The scores of control subjects C 21 and C 25 were again definitely in the range of those of heterozygotes and the score of subject $\mathrm{P} 4$ was in the range of that of the control group. Subject P 6 showed an excessively high score when calculated by use of formula 2 only.

Other discriminatory analysis that included control subjects $\mathrm{C} 21$ and $\mathrm{C} 25$ was performed. The coefficients obtained are shown in table III (formulas 3 and 4). The results of statistical evaluation of the discriminant scores obtained with these formulas are shown in table IV. The discriminant scores of subjects $\mathrm{C} 21$ and C 25 (8.01 and 9.78 with formula 3, and 10.29 and 7.73 with formula 4 , respectively) were the highest of the control group and were the only ones that overlapped with those of the parents.

A final discriminatory analysis was performed including subjects $\mathrm{C} 21$ and $\mathrm{C} 25$ in the parent (or hetero

Table III. Oral L-phenylalanine load. Results of discriminatory analysis

\begin{tabular}{|c|c|c|c|c|c|c|c|c|}
\hline \multirow{2}{*}{$\begin{array}{l}\text { Variables: } \\
\text { concentration after load }(h)\end{array}$} & \multicolumn{4}{|c|}{ Phenylalanine } & \multicolumn{4}{|c|}{ Tyrosine } \\
\hline & 1 & 2 & 3 & 4 & 1 & 2 & 3 & 4 \\
\hline \multicolumn{9}{|l|}{$\begin{array}{l}\text { Coefficients } \\
\text { A. C } 21, \text { C } 25 \text {, an }\end{array}$} \\
\hline Formula 1 (with P 6) & 0.63 & 1.06 & 4.24 & -4.92 & -0.39 & -5.76 & -10.77 & 11.95 \\
\hline Formula 2 (without P 6) & 0.63 & 0.21 & 3.57 & -2.11 & -3.43 & -1.76 & -5.44 & 4.93 \\
\hline \multicolumn{9}{|l|}{$\begin{array}{l}\text { B. G } 21 \text { and C } 25 \text { included, } \\
\text { P } 4 \text { excluded }\end{array}$} \\
\hline Formula 3 (with P 6) & 0.72 & -0.71 & 2.56 & -1.66 & -4.42 & 1.30 & -3.73 & 4.17 \\
\hline Formula 4 (without P 6) & 0.74 & -1.48 & 2.07 & 0.62 & -7.30 & 4.81 & 0.63 & -1.69 \\
\hline $\begin{array}{l}\text { C. Formula } 5 \\
\text { (for explanation see text) }\end{array}$ & 0.65 & 0.36 & 3.86 & -2.56 & -3.10 & -2.30 & -6.54 & 5.82 \\
\hline
\end{tabular}

Remarks: With these formulae one calculates a discriminant score for each subject. It is obtained by multiplying the phenylalanine and tyrosine concentrations with the respective coefficient and by adding these products.

Notes table IV:

124 controls: $\mathrm{C} 21$ and $\mathrm{C} 25$ excluded 26 controls: $\mathrm{C} 21$ and $\mathrm{G} 25$ included

17 parents: $P 4$ and $P 6$ excluded

18 parents: $P 4$ excluded

25 'controls' (for formula 5 only): 24 controls (C 21 and C 25 excluded), P 4 included in the 'control' group.

19 'heterozygotes' (for formula 5 only): 17 parents (P 4 and P 6 excluded), C 21 and C 25 included in the 'heterozygote' group.

${ }^{2} \mathrm{t}$ according to SNEDECOR and Cochran ([26], chapter 4.10, p. 104). P of all ts $\ll 0.001$.

${ }^{3}$ Discriminatory power according to Penrose [20].

${ }^{4}$ Critical line according to Penrose $[20]\left(\mathrm{C}=\left[\mathrm{M}_{1} \mathrm{~s}_{2}+\mathrm{M}_{2} \mathrm{~s}_{1}\right] /\left[\mathrm{s}_{1}+\mathrm{s}_{2}\right]\right)$ at 7.05.

${ }^{5}$ Critical line at 7.56.

${ }^{6}$ Critical line at 7.88 . 
Table IV. Oral L-phenylalanine load. Results of statistical evaluation by different criteria

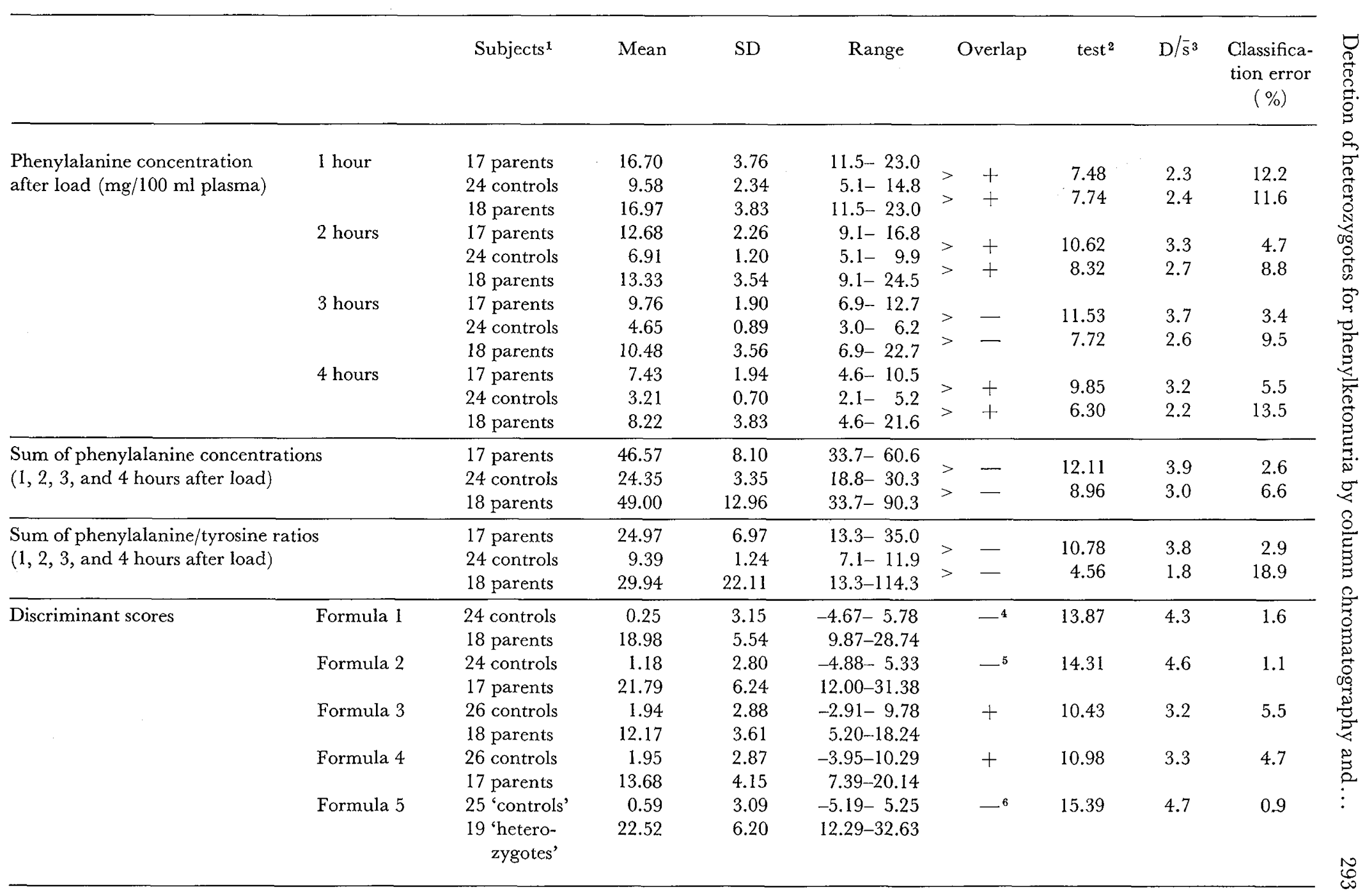




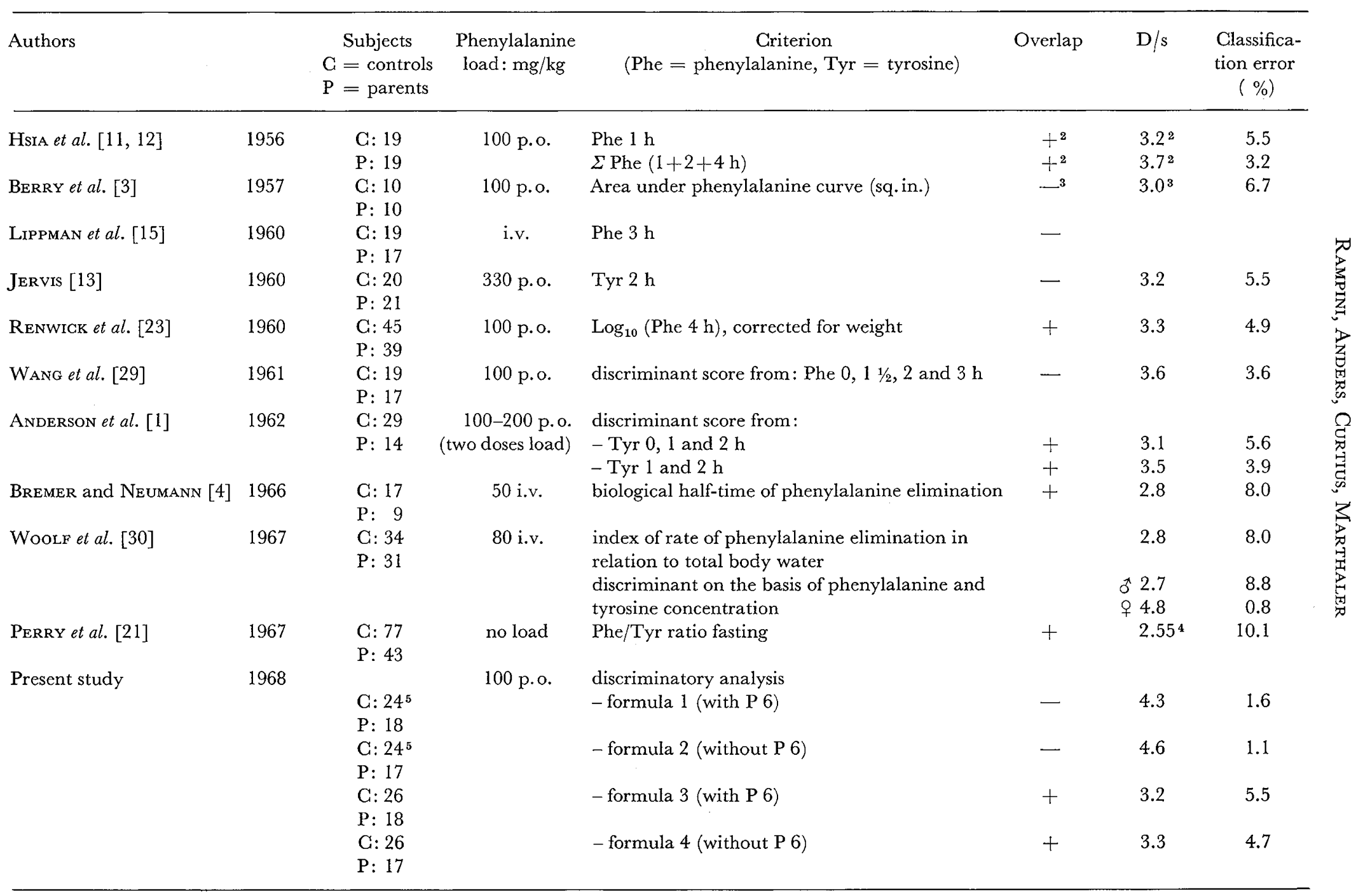


zygote) group and subject $\mathrm{P} 4$ in the control group. The coefficients obtained in this way (formula 5, table III) were similar to those of formula 2 (table III). Statistical evaluation of the scores calculated with this formula is shown in table IV.

\section{Discussion}

In this study, concentrations of phenylalanine and tyrosine in plasma after an oral phenylalanine load were determined by column chromatography and the results were evaluated by discriminatory analysis. Column chromatography seemed to be more accurate and advantageous than other techniques because both amino acids could be determined in one step.

In control subjects C 21 and C 25, the values (phenylalanine and tyrosine concentrations, sum of the phenylalanine concentrations and sum of the phenylalanine/tyrosine ratios after loading) were very unusual compared with those of the other 24 controls. Since the values were definitely within the range of those of the heterozygotes, these subjects were considered as such. We thought, therefore, that for examination of a possible heterozygote, it would be appropriate to use the calculations that were performed, excluding these two controls as well as the parent $\mathrm{P} 4$ (paternity excluded by blood group analysis).

To determine whether discriminatory analysis allows a better separation of the heterozygotes from the control subjects than other criteria, the index of PENROSE [20] was used:

$\mathrm{D} / \overline{\mathrm{s}}=\frac{\mathrm{M}_{1}-\mathrm{M}_{2}}{1 / 2\left(\mathrm{~s}_{1}+\mathrm{s}_{2}\right)}$ where $\begin{aligned} \mathrm{M} & =\text { mean value and } \\ \mathrm{s} & =\text { standard deviation. }\end{aligned}$

This equation represents the difference of the mean values divided by the mean of the standard deviations of the two groups. With this index, the discriminatory power of a criterion is expressed as a number. The $\mathrm{D} / \overline{\mathrm{s}}$ of the criteria used in this study, as well as other statistical data, is shown in table IV. Subjects C 21, C 25, and P 4 were excluded from these calculations. Sub-

\footnotetext{
Notes table V:

1 Only PerRy et al. [21] used column chromatography.

21 control excluded (probable heterozygote).

31 control excluded (probable heterozygote).

43 controls excluded (probable heterozygotes).

52 controls excluded (probable heterozygotes).
}

jects C 21 and C 25 were included in the control group for calculation of formulas 3 and 4 only. In contrast, the calculations were made with and without the parent P 6 (mother with unusually high phenylalanine and low tyrosine values after loading). The index of Penrose of the discriminatory analysis was superior to that of the other criteria, especially if subject P 6 was included in the calculations (formulas 1 and 2).

As indicated by the classification error (table IV) and by figure 3, even with these formulas (subjects C 21 and C 25 excluded), some overlapping might be expected in a larger number of subjects. The variability in the heterozygotes was larger than in the controls, who represented a homogenous group (figs. 1, 2, and 3 ). It is conceivable that this observation indicates a genetic heterogeneity of the alleles on the phenylketonuria locus $[24,30]$ or the presence of other modifying genes.

The results of other investigators and of our study are summarized in table $\mathrm{V}$. If formula 1 or preferably the more logical formula 2 , which we recommend for practical use, is applied, only the results of WooLF [30], who used an intravenous load, were partially better (in females) than the results in the present study. If formulas 3 and 4, which were calculated including the unusual control subjects C 21 and C 25, are applied, the results are in the range of those of other authors. In some of these studies, unusual controls were also excluded.

The use of column chromatography and of discriminatory analysis seems, therefore, to improve the possibility of detection of heterozygotes for the gene of phenylketonuria.

\section{Summary}

Phenylalanine $(100 \mathrm{mg} / \mathrm{kg}$ ) was given orally to $26 \mathrm{con}$ trols and 19 heterozygotes. Concentrations of phenylalanine and tyrosine in plasma were determined by column chromatography before and 1, 2, 3, and 4 hours after loading. Using as criteria the phenylalanine concentrations, the sum of the phenylalanine values and the sum of the phenylalanine/tyrosine ratios after loading, two controls were considered to be heterozygotes. A father of a patient had, on the contrary, values within the range of the controls; paternity was excluded by blood group analysis. These three subjects were therefore excluded from discriminatory analysis. Another heterozygote had unusually high values. Discriminatory analysis was performed with and without this subject. The index of Penrose (D/s) shows that a better separation of the heterozygotes from the control subjects is obtained with discriminatory analysis than with other criteria [34]. 


\section{References and Notes}

1. Anderson, J.A.; Gravem, H.; Ertel, R. and Fisch, R.: Identification of heterozygotes with phenylketonuria on basis of blood tyrosine responses. J.Pediat. 61: 603 (1962).

2. Benson, J.V., Jr.; Cormick, J. and Patterson, J.A.: Accelerated chromatography of amino acid associated with phenylketonuria, leucinosis (Maple Syrup urine disease), and other inborn errors of metabolism. Anal. Biochem. 18: 481 (1967).

3. Berry, H.; Sutherland, B. and Gưest, G. M.: Phenylalanine tolerance tests on relatives of phenylketonuric children. Amer.J. hum. Genet. 9: 310 (1957).

4. Bremer, H.J. and Neumann, W.: Tolerance of phenylalanine after intravenous administration in phenylketonurics, heterozygous carriers, and normal adults. Nature, Lond. 209: 1148 (1966).

5. Cahalane, S.F.: Phenylketonuria. Mass screening of newborns in Ireland. Arch. Dis. Ghildh. 43: 141 (1968).

6. Garson, N.A.J.; Carré, I.J. and Neill, D.W.: Results of routine screening for phenylketonuria in early infancy, Northern Ireland (1960-67). Arch. Dis. Childh. 43: 145 (1968).

7. Centerwall, W.R.; Berry, H.K. and Woolf, L. I. : Detection. Screening programs; in Phenylketonuria (ed. Lyman, F.L.), p.115 (Thomas, Springfield, Ill. 1963).

8. Cohen, B. E.; Szeinberg, A.; Peled, I.; Szeinberg, B. and BAR-OR, R.: Screening program for early detection of phenylketonuria in the newborn in Israel. Israel J.med. Sci. 2: 156 (1966).

9. Hsia, D. Y.-Y.: Phenylketonuria: The phenylalanine-tyrosine ratio in the detection of the heterozygous carrier. J. ment. Def. Res. 2: 8 (1958).

10. Hsia, D.Y.-Y. and Driscoll, K.W.: Detection of the heterozygous carriers of phenylketonuria. Lancet ii: 1337 (1956).

11. Hsia, D.Y.-Y.; Driscoll, K.W.; Troll, W. and Knox, W.E.: Detection by phenylalanine tolerance tests of heterozygous carriers of phenylketonuria. Nature, Lond. 178: 1239 (1956).

12. Hsia, D.Y.-Y. and Parne, R.S.: Phenylketonuria: Detection of the heterozygous carrier. J. ment. Def. Res. 1: 53 (1957).

13. Jervis, G.A.: Detection of heterozygotes for phenylketonuria. Clin. chim. Acta 5: 471 (1960).

14. Knox, W.E. and Messinger, E. C.: The detection in the heterozygote of the metabolic effect of the recessive gene for phenylketonuria. Amer.J.hum. Genet. 10: 53 (1958).

15. Lippman, R.W.; Shaw, K.N.F.; Perry, T.L.L.; Gutenstein, M.; v. Redlich, D.; Moore, P. and
WALKer, D.: Identification of phenylketonuria heterozygotes by an intravenous phenylalanine tolerance test. Clin. Res. 8: 142 (1960).

16. Lubs, H. und Heilmann, H.H.: Säulenchromatographische Bestimmung von Phenylalanin und Tyrosin. Naturwissenschaften 52: 392 (1965).

17. MacCready, R.A. and Hussey, M.G.: Newborn phenylketonuria detection program in Massachusetts. Amer.J. publ. Hlth 54: 2075 (1964).

18. Massachusetts Department of Public Health: Screening program for phenylketonuria and other inborn errors of metabolism. New Engl.J.Med. 273: 109 (1965).

19. Mechanic, G.; Erron, M.L. and Shih, V.E.: A rapid quantitative estimation of tyrosine and phenylalanine by ion-exchange chromatography. Anal. Biochem. 16: 420 (1966).

20. Penrose, L. S. : Measurement of pleiotropic effects in phenylketonuria. Ann. Eugen. 16: 134 (1951).

21. Perry, T.L.; Hansen, S.; Trschler, B. and BunTING, R.: Determination of heterozygosity for phenylketonuria on the amino acid analyzer. Clin. chim. Acta 18: 51 (1967).

22. Perry, T.L.; Trschler, B.; Hansen, S. and MaGDougall, L.: A simple test for heterozygosity for phenylketonuria. Clin.chim. Acta 15: 47 (1967).

23. Renwick, J.H.; Lawler, S. D. and Cowie, V.A.: Phenylketonuria: A linkage study using phenylalanine tolerance tests. Amer.J.hum. Genet. 12: 287 (1960).

24. Rosenblatt, D. and Scriver, C. R.: Heterogenity in genetic control of phenylalanine metabolism in man. Nature, Lond. 218: 677 (1968).

25. Shin, V.E.; Efron, M.L. and Mechanic, G.L.: Rapid short-column chromatography of amino acids. A method for blood and urine specimens in the diagnosis and treatment of metabolic disease. Anal. Biochem. 20: 299 (1967).

26. SNedecor, G.W. and Cochran, W.G.: Statistical methods, 6th ed. (Iowa State University Press, Ames, Io. 1967).

27. Spackman, D.H.; Stein, W.H. and Moore, S.: Automatic recording apparatus for use in the chromatography of amino acids. Anal. Chem. 30: 1190 (1958).

28. Sydnes, S. and Følling, A.: On detection of heterozygotes for phenylpyruvic oligophrenia. Scand. J. clin. Lab. Invest. 14: 44 (1962).

29. WANG, H.L.; Morton, N.E. and Waisman, H. A.: Increased reliability for the determination of the carrier state in phenylketonuria. Amer.J.hum. Genet. 13: 255 (1961).

30. Woolf, L.I.; Granston, W.I. and Goodwin, B.L.: Genetics of phenylketonuria. Nature, Lond. 213: 882 (1967). 
Detection of heterozygotes for phenylketonuria by column chromatography and...

31. Bio Cal Instruments GmbH, Munich/Germany, model BC 200.

32. Probability to include 0 heterozygotes $=59.2 \%$, $1=31.4 \%, 3=1.3 \%$ and 4 or more $0.2 \%$.

33. Father (P 4): $\mathrm{A}_{1}, \mathrm{MsNs}, \mathrm{P}_{1}+$, ccddee, $\mathrm{K}-, \mathrm{Fy}^{\mathrm{a}}-$. Mother: $\mathrm{A}_{1}, \mathrm{MsMs}, \mathrm{P}_{1}+, \mathrm{CG}^{\mathrm{w}} \mathrm{DEe}, \mathrm{K}-$, Fya ${ }^{\mathrm{a}}$. Child: $\mathrm{A}_{\mathbf{1}}, \mathrm{MsNs}, \mathrm{P}_{\mathbf{1}}+, \mathrm{CC}^{\mathrm{w}}$ Dee, $\mathrm{K}-, \mathrm{Fy}^{\mathrm{a}}+$.
34. The authors wish to thank Dr. M. Metaxas of the Red Cross Blood Bank, Zurich, for blood group analysis, and Miss. R. Gur for technical assistance.

35. Requests for reprints should be addressed to: SERGio RampinI, M.D., Universitäts-Kinderklinik, Steinwiesstrasse 75, 8032 Zurich (Switzerland). 